\title{
ВОСПРИЯТИЕ ФАЛЬШИВОЙ ДРУЖБЫ РУССКИМИ И ПОЛЯКАМИ (НА МАТЕРИАЛЕ ИНТЕРНЕТ-МЕМОВ)
}

\section{Depiction of False Friendship Based on Russian and Polish Internet Memes}

Keywords: demotivator, false friendship, internet meme, Russian language, Polish language

Contact: Uniwersytet Śląskiw Katowicach; gabriela.kamionka007@gmail.com

Интернет-мем «представляет собой уникальный недавно возникший феномен компьютерной коммуникации. Несмотря на свою недолгую историю, (он) стал массовым и высоко популярным явлением в интернет-коммуникации» (Канашина 2017: 1). Надо обратить внимание, что самое определение мема было введено биологом Р. Докинзом в его книге Эгоистичный мем. Автор считает, что новым репликатором, кроме гена, который появился в мире, является мем. По мнению Докинза, примерами мемов являются мелодии, идеи, общие фразы, стили одежды, способы изготовления кастрюль или построения арочных сводов (Dawkins 2010: 244).

Характерной особенностью интернет-мемов является то, что они могут состоять из знаков языковых так же, как визуальных. Они пользуются популярностью в определенное время. Быстро забываются людьми, поэтому каждый из них борется за свое выживание в сети. Интернет-мемы, которые потеряли свою популярность, не уничтожаются. Они размещаются на сайтах и ожидают момента, когда они снова станут популярными (Walkiewicz 2012: 51).

Теме типологии интернет-мемов посвящено значительное количество публикаций, которые объясняют, что классификация может быть основана на различных критериях таких, как: способ выражения мема, источник его возникновения, структура мема (Щурина 2014: 87). Наиболее распространенным примером интернет-мема считается креолизованный мем, который состоит из вербальной и невербальной частей (рисунок, фотография). Типичным креолизованным мемом является демотиватор. Это изображение, «состоящее из 
картинки в черной рамке и комментирующей еe надписи-слогана» ${ }^{1}$. Демотиваторы появились в США благодаря американской компании, которая начала создавать их с 1998 года. Это пародия на мотивационные плакаты, «которые были призваны побудить обучаемых к успешной учебе» (Лутовинова 2016: 29). Они должны были также побуждать людей работать. Тем не менее, мотивационные плакаты были скучными. Они призывали школьников более к пародированию, чем к следованию за пропагандируемыми ценностями (Щурина 2010: 84). Демотиваторы должны были выражать пессимистический образ мира, иными словами, они выполняли противоположную функцию, чем мотивационные плакаты. В настоящее время демотиваторы обычно ссылаются на текущие события или затрагивают те темы, которые являются наиболее популярными.

Очень важную роль в хорошей интерпретации интернет-мемов играет концепция языковой картины мира. Надо подчеркнуть, что существует много определений ЯКМ. Одна из точек зрения принадлежит Е. Бартминьскому. По мнению автора, существуют два варианта представления языкового образа мира: «субъектный» и «объектный». Можно это «обозначить терминами видение мира (польск. wizja świata) - это видение чье-то, оно подразумевает смотрение, а следовательно, и смотрящего субъекта и картина мира (польск. obraz świata) являющаяся, конечно, также результатом чьего-то видения мира» (Бартминьский 2005: 87). Однако основной тезис, формулирующий ЯКМ, был создан В. фон Гумбольдтом. Он утверждал, что языки на самом деле «являются средством обнаружения неизвестных ранее правд» (Anusiewicz, Dąbrowska, Fleischer 2000: 24-25). Ученый заявил, что каждый естественный язык имеет индивидуальный взгляд на мир. По нашему мнению, очень интересный взгляд на ЯКМ выдвинула В. А. Маслова. Она считает, что картина мира является «одним из фундаментальных понятий, описывающих человеческое бытие. Картина мира отражается в содержательной стороне языка этноса. Ее анализ помогает понять в чем отличаются национальные культуры» (Маслова 2005: 48). Она также обращает внимание на термин наивная картина мира. Как пишет Ю. Д. Апресян, ЯКМ является наивной, потому что она создана из точек зрения людей (Bartmiński 2006: 14).

Объектом нашего исследования являются русские и польские интернетмемы, иллюстрирующие фальшивую дружбу. Мы попытаемся найти сходства и различия в восприятии фальшивой дружбы на основании нескольких русских и польских демотиваторов.

\footnotetext{
${ }^{1}$ Режим доступа: https://unotices.com/page-answer.php?id=9752 (2020-04-22). 
В жизни человека дружба очень важна. Без нее наша жизнь была бы пустой и бессмысленной. К сожалению, оказывается, что вокруг нас есть и фальшивые друзья. Это болезненная правда, но в то же время очень реальная. Первым примером, который позволит нам определить черты такой дружбы будет русский демотиватор.

Часто мы думаем, что вокруг нас есть настоящие друзья. Однако со временем оказывается, что действительность другая. В начале мы сосредоточимся на том, как графика отражает фальшивого друга. На картинке мы видим женщину, которая из-за ложной дружбы не хочет жить. Когда ей понадобилась помощь, друзья отвернулись от нее. Данная мысль также выражена предложением, которое находится под картинкой. Особенно интересным предметом, используемым автором этого мема,

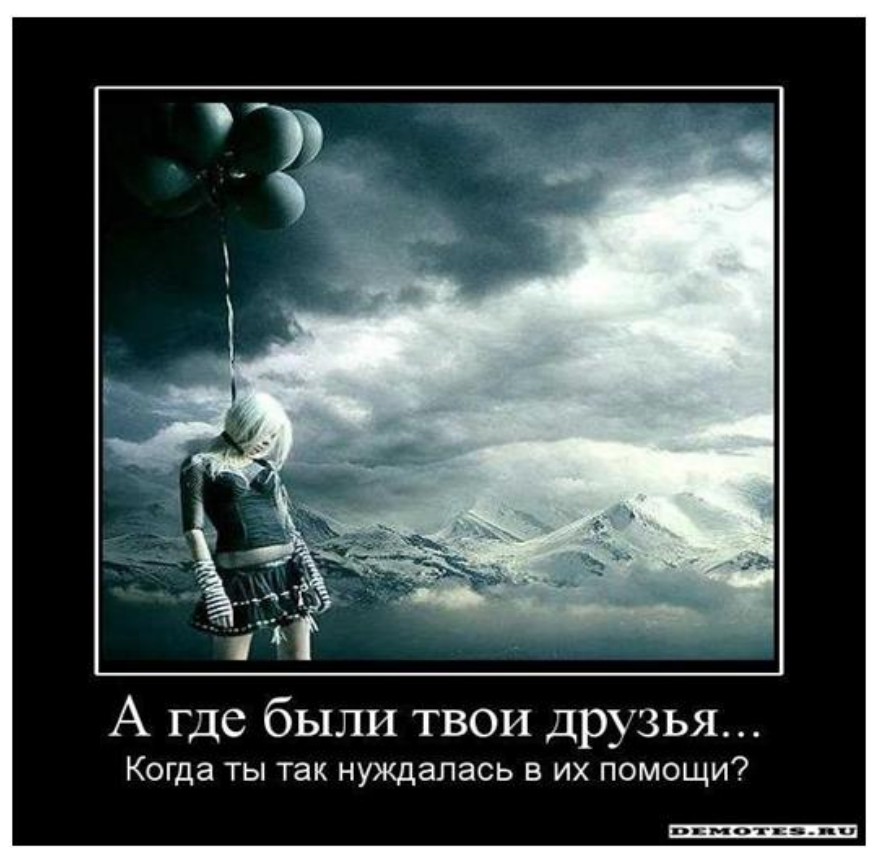

http://demotes.ru/demotivatori_o_drujbe/page/5/ являются шарики. По нашему мнению, они символизируют фальшивых друзей. Мы видим, как веревки шариков окружают шею женщины. Таким образом можно сделать вывод, что шарики, летающие в воздухе, являются фальшивыми друзьями, которые убегают, когда у нас возникнут проблемы в жизни.

Переходим теперь к рассмотрению, как фальшивый друг представлен в демотиваторах с использованием изображения сказочных персонажей. Героями сказок могут быть, например, предметы, животные, воплощающие человеческие качества. В них разные темы реальной жизни. В основном мы фокусируемся на теме, которая нас больше всего интересует, то есть на дружбе. В детстве мы смотрели много сказок, в которых лейтмотивом была настоящая дружба, но сейчас мы сосредоточимся на конкретной сказке, из которой был использован один герой в следующем демотиваторе. 
Персонаж на картинке происходит из советского мультфильма «ВинниПух» по сказке А. Милна. Это маленький поросенок, который является самым близким другом Винни-Пуха. Стоит заметить, что поросенок - это детеныш свиньи. Свинья ассоциируется с нечистым животным. Именем этого животного часто пользуемся, чтобы описать другого человека, если он своим поведением сильно нас расстроил. Как определено в словаре, свинья - это «грязный, неопрятный, человек с низменными привычками», а также

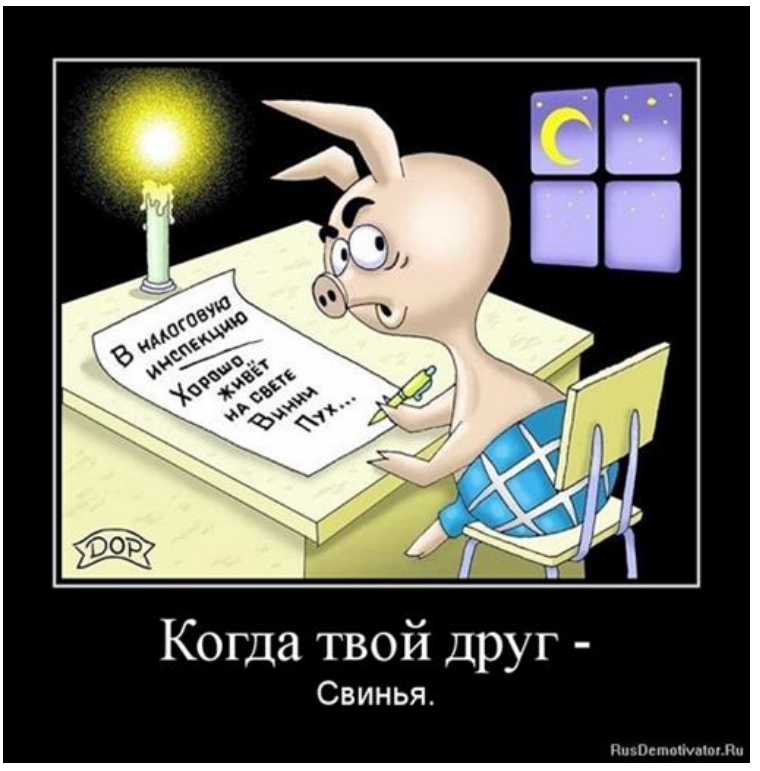
http://demotivatori.net/demotivatori_podrobneje.php ?id $=6088$ «поступающий низко, подло, грубо» (Кузнецов 2006: 1160). Автор демотиватора отмечает, что наш наилучший друг может оказаться свиньей. Его мысль показывает этот интернет-мем. Друг Винни-Пуха подсылает к нему налоговую инспекцию. По нашему мнению, он завидует своему другу хорошей жизни. Этот демотиватор точно отражает фальшивую дружбу. К сожалению, даже друг может вставлять нам палки в колеса (Тихонов, Ломов 2007: 112). Фразеологизм и вышеупомянутый интернет-мем показывают, что настоящий друг может оказаться нашим врагом.

Теперь мы рассмотрим другой пример, который также можно сравнить с фразеологизмом.

На первый взгляд, можно предполагать, что автор использовал иронию в этом демотиваторе. Слова, содержащиеся в интернет-меме, описывают настоящего друга, который всегда заботится о нас. Другое подсказывает нам визуальный компонент этого демотиватора. Мы видим письмо, написанное другом. Он сообщает, что его друг вызван к боссу. Судя по постскриптум, у него большая проблема с работой. В такой ситуации очевидно, что наш лучший друг

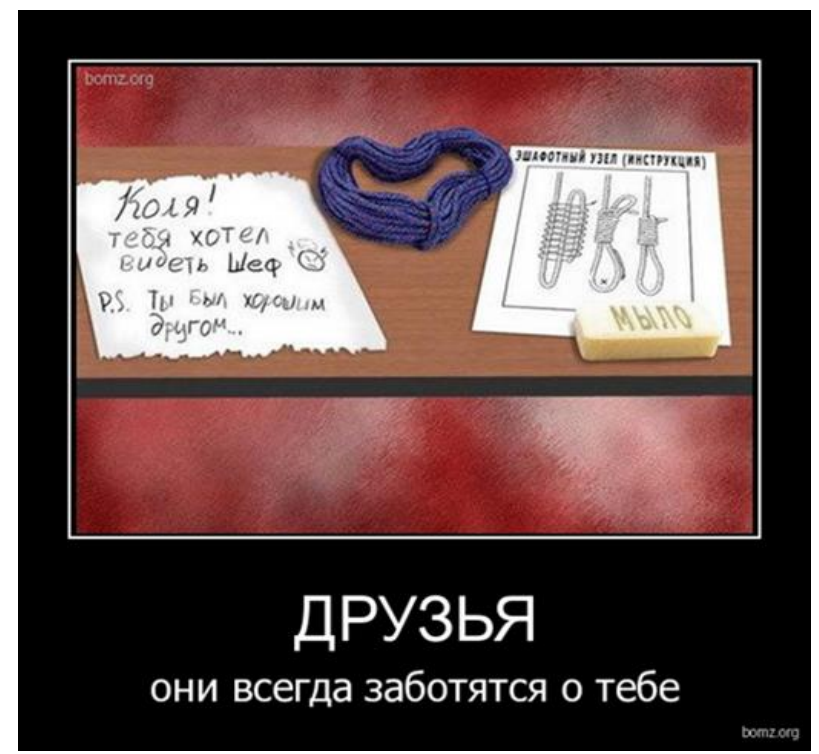

http://prikollol.ru/demotivatory-pro-druzej/ 
должен поддержать нас, а не как говорит демотиватор, наслаждаться нашими неудачами. Следовательно, мы приходим к выводу, что фальшивый друг помогает погрузить человека, который считает его наилучшим другом. На это указывает инструкция, как сделать эшафотный узел. Автор интернет-мема подчеркнул, что друг может оказаться ужасным человеком, который склоняет к плохим поступкам, в этом случае повеситься. Также характерным предметом является мыло. Оно может символизировать друга, который, пользуясь фразеологизмом, умывает руки от наших проблем.

Следующим нашим примером будет польский демотиватор, в котором автор использовал символику голубя.

Как известно, голубь - это символ любви и верности (Kopaliński 1990: 96-97). Надпись демотиватора содержит польский фразеологизм gruchać jak dwa gołabki, который означает, что между людьми царит согласие, симпатия, любовь ${ }^{2}$. Однако это противоречит сообщению демотиватора. Обычно люди испытывают положительные эмоции по отношению к этому животному. К сожалению, есть одна вещь, которая беспокоит многих людей в голубях. Это отметил автор демотиватора, сравнивая с этим фальшивого друга.

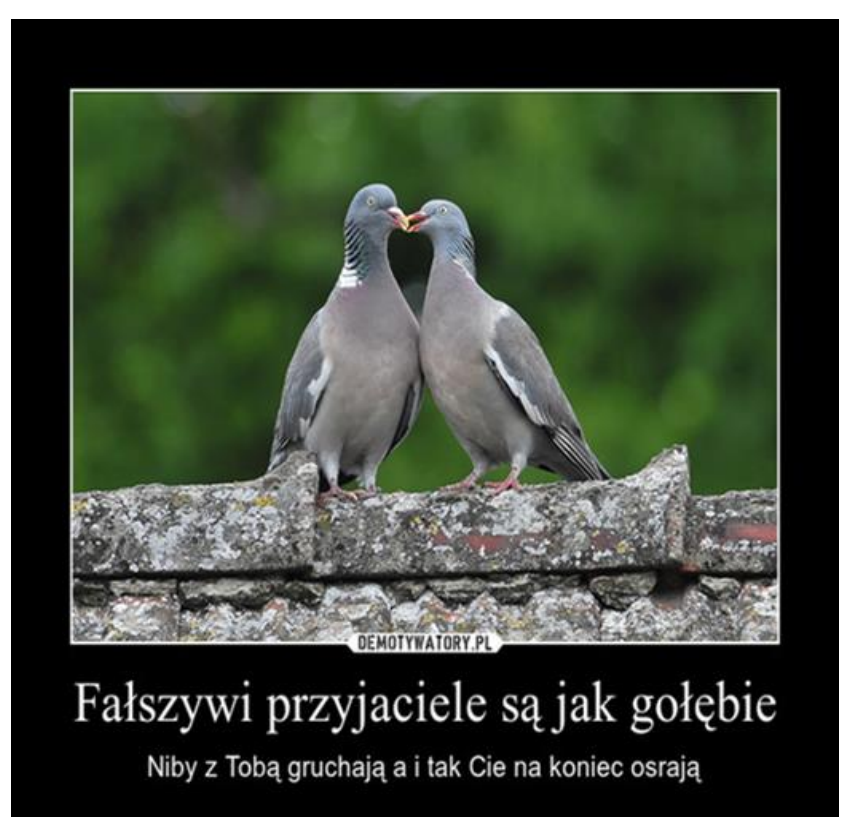

https://demotywatory.pl/4360035/Falszywi-przyjaciele-sajak-golebie

Мы наблюдаем, что голуби испражняются в общественных местах, что раздражает людей. В демотиваторе это поведение выражается вульгарно с помощью слова оsrać (рус. обосрать), другими словами: «пренебречь, публично критиковать» (Żmigrodzki 2007). Фальшивые друзья обычно создают видимость настоящего, чтобы извлекать из нас, например, ценную информацию, наши мнения о конкретном человеке или секреты, чтобы потом использовать их против нас. Изображение голубя, содержащееся в меме, предназначено для того, чтобы показать получателю, что фальшивая дружба обычно сперва кажется красивой. Через некоторое время, когда нашему фальшивому другу не нужны наши знания, он забывает о нас и заканчивает нашу дружбу.

\footnotetext{
${ }^{2}$ Stownik frazeologiczny. Режим доступа: https://phrasebook_pl.enacademic.com/922/go\%C5\%82\%C4\%85bek
} (2020-04-19). 
Очень часто в польских демотиваторах, описывающих фальшивого друга, используется изображение животных, чтобы помочь получателю хорошо истолковать такой интернет-мем. Теперь примером будет интернет-мем, который описывает, как действительно выглядит дружба в настоящее время.

Сегодня очень трудно встретить отношения между людьми, которые Przyjaźń w dzisiejszych czasach можно назвать настоящей дружбой, о чем свидетельствует этот мем. Люди представляют дружбу как отношения, основанные на взаимной доброте. Иногда нам кажется, что рядом с нами есть друг, которому мы можем безоговорочно доверять. Однако реальность оказывается иной, как указывает вторая картинка. Она представляет двух змей, которые вызывают негативные ассоциации у людей. Змея является символом https://www.blasty.pl/21442/przyjazn-w-dzisiejszychсмерти, опасности, обмана и т. д. По
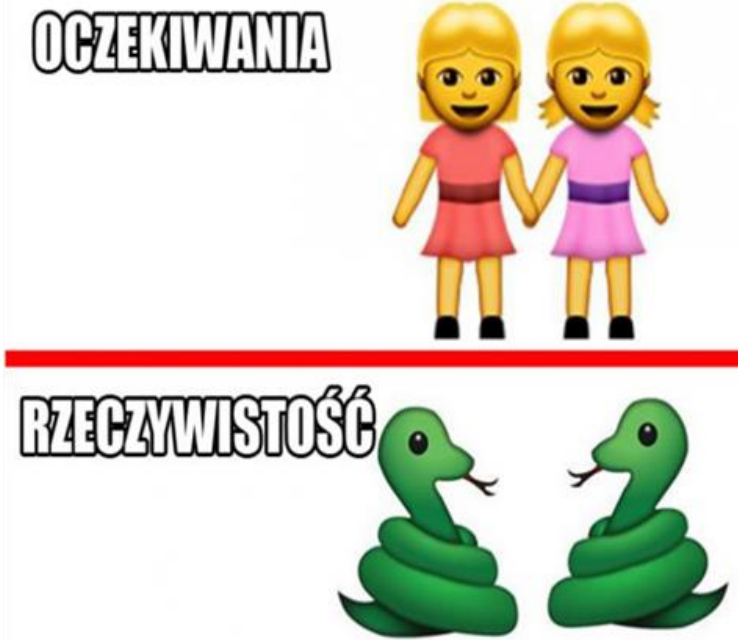
словам святого Августина, гадюка является символом зависти ${ }^{3}$. Змея также описывает злого коварного хитрого человека. Поэтому автор, желая показать фальшивых друзей, использовал изображение этого животного. По мнению создателя интернет-мема, сегодняшние друзья похожи на змей, которые только смотрят, как уничтожать друг друга. На наш взгляд, причиной такого поведения является ревность, которой не существует в настоящей дружбе.

Человек борется с различными проблемами в своей жизни, которые связаны, например, с семьей, работой. В такие моменты очень важно иметь вокруг себя настоящего друга. К сожалению, следующий демотиватор показывает, что сегодня трудно найти такого друга. Оказывается, даже на работе настоящий друг может превратиться во врага.

Этот интернет-мем показывает отношения между двумя друзьями, которые работают вместе в корпорации. Прежде всего, надо обратить внимание на выражения лица этих двух девушек. Они улыбаются друг другу. Однако одна

\footnotetext{
${ }^{3}$ Универсальная энииклопедия Кирилла и Мефодия. Режим доступа: https://megabook.ru/article/\%D0\%97 \%D0\%BC\%D0\%B5\%D1\%8F\%20(\%D1\%81\%D0\%B8\%D0\%BC\%D0\%B2\%D0\%BE\%D0\%BB (2020-04-19). 
улыбка настоящая, а вторая явно ложная. Об этом свидетельствует расположение губ этих женщин. Также поднятые вверх руки символизируют, что люди, изображенные на картинке, являются хорошими друзьями. Однако это всего лишь иллюзия. Это предполагает отношение второй женщины, которая воткнула нож в спину (Тихонов, Ломов 2007: 172) своей подруге. На этом демотиваторе это показано дословно. Однако, по нашему мнению, автор мема имел в виду польский фразеологизм wbić

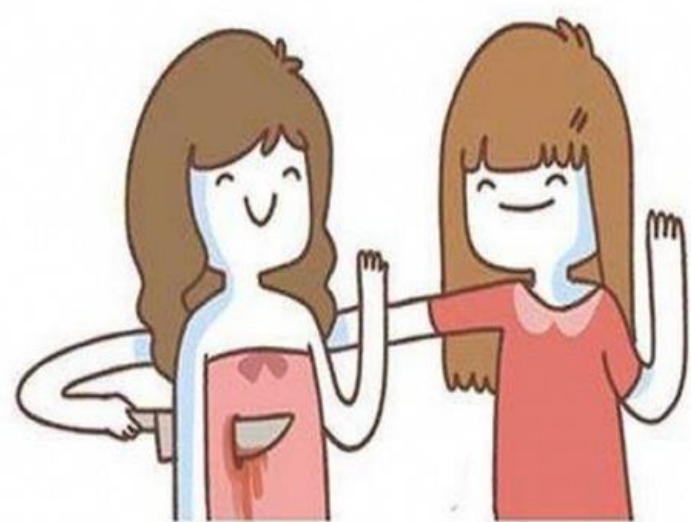

\section{Przyjaźń w korpo}

https://www.blasty.pl/17/przyjazn-w-korpo komuś noż w plecy, который иллюстрирует эту ситуацию. Этот фразеологизм описывает человека, который «w haniebny sposób przyczynił się do czyjejś klęski, do czyjegoś niepowodzenia» (Bąba, Liberek 2002: 456). Следует также отметить, что эти два человека работают в корпорации, где командная работа очень важна. Благодаря взаимному сотрудничеству достигаются лучшие результаты. Однако фальшивый друг не обращает на это внимания. Он заботится только о себе. К сожалению, иногда человек, которого мы считаем другом, может предать нас. Коварным образом способствует нашему поражению. Скорее всего, это из-за ревности, которая раскрывает настоящее лицо нашего друга. Оказывается, этот человек действительно наш фальшивый друг, который терпеть не может, что мы лучше работаем, чем он или быстрее двигаемся по службе. Этот демотиватор также указывает на то, что иногда трудно оценить намерения близкого нам человека. Мы видим улыбающуюся женщину, которая создает видимость хорошего друга, и без каких-либо сомнений втыкает нож в спину своей подруге. Из этого вытекает, что эта ревность является основной причиной разрыва дружбы, которая довольно часто является показателем фальшивой дружбы в польских интернет-мемах.

В ходе исследования мы заметили, что часть польских демотиваторов относится к популярным фразеологизмам, в то время как в русских существует множество символов и предметов. Характерной чертой русских и польских демотиваторов является использование животных. Можно сказать, что русские и польские демотиваторы отражают действительность не только при помощи визуального кода, но также посредством языка. Каждый язык по-разному интерпретирует действительность. В связи с этим, он показывает различные 
способы видения и понимания мира. Это обычно обусловлено культурой, но также грамматическими и лексическими значениями. Поэтому русские и польские интернет-мемы отличаются друг от друга в графическом и лингвистическом отношении, хотя фальшивая дружба интерпретируется в общем одинаково как в России, так и в Польше.

\section{Summary}

The purpose of this article is to analyse Russian and Polish internet memes, which have become a very popular phenomenon in internet communication. Examples used in the work are mostly demotivators about false friendship. In the first part, attention was focused on the terminology associated with internet memes and the linguistic worldview. In the second part, there was an analysis of Russian and Polish demotivators that the best reflect the features of false friendship. It was to compare which rethorical terms or graphic sings both cultures used to show false friendship using internet memes.

\section{Литература}

Бартминьский, Е. Точка зрения, перспектива, языковая картина мира. Пер. М. В. Завьяловой. In: Бартминьский, Е. (ed.) Языловой образ мира: очерки по этнолингвистике. Москва, 2005, с. 87-104.

Канашина, С. В. Что такое интернет-мем? Научные ведомости Белгородского государственного университета. 2017 (36), с. 84-90.

Кузнецов, С. А. Большой толковый словарь русского языка. Санкт-Петербург: Норинт, 2006.

Лутовинова, О. В. Демотиватор как вид сетевого творчества. Вестник Волгоградского государственного университета. 2016 (3), с. 28-36.

Маслова, В. А. Когнитивная лингвистика. Минск: ТетраСистемс, 2005.

Тихонов, А. Н., Ломов, А. Г. Фразеологический словарь русского языка. Москва: Русский язык - Медиа, 2007.

Щурина, Ю. В. Интернет-мемы: проблема типологии. Вестник Череповеикого государственного университета. 2014 (6), с. 85-89.

Щурина, Ю. В. Комические креолизованные тексты в интернет-коммуникации. Вестник Новгородского государственного университета им. Ярослава Мудрого. 2010 (57), с. 82-86. 
Anusiewicz, J., Dąbrowska, A., Fleischer, M. Językowy obraz świata i kultura: projekt koncepcji badawczej. In: Dąbrowska, A., Anusiewicz, J., Fleischer, M. (eds.) Język a Kultura. T. 13. Wrocław: Wydawnictwo Uniwersytetu Wrocławskiego, 2000, c. 24-31.

Bartmiński, J. Językowe podstawy obrazu świata. Lublin: Wydawnictwo Uniwersytetu Marii Curie-Skłodowskiej, 2006.

Bąba, S., Liberek, J. Słownik frazeologiczny współczesnej polszczyzny. Warszawa: PWN, 2002.

Dawkins, R. Samolubny gen. Przeł. M. Skoneczny. Warszawa: Prószyński i S-ka, 2010.

Kopaliński, W. Stownik symboli. Warszawa: Rytm, 1990.

Walkiewicz, A. Czym są memy internetowe? Rozważania z perspektywy memetycznej. 2012 (14), c. 49-71.

\section{Интернет-источники}

Режим доступа: https://unotices.com/page-answer.php?id=9752 (2020-04-22).

Универсальная энщиклопедия Кирилла и Мефодия. Режим доступа:

https://megabook.ru/article/\%D0\%97\%D0\%BC\%D0\%B5\%D1\%8F\%20(\%D1

$\% 81 \%$ D0\%B8\%D0\%BC\%D0\%B2\%D0\%BE\%D0\%BB (2020-04-19).

Stownik frazeologiczny. Режим доступа: https://phrasebook_pl.enacademic.com/922/ go\%C5\%82\%C4\%85bek (2020-04-19).

Wielki słownik języka polskiego PAN. Режим доступа: https://wsjp.pl/index.php? pokaz=autorzy $\& \mathrm{l}=1 \&$ ind $=0$ ?pwh=0 (2020-04-22). 